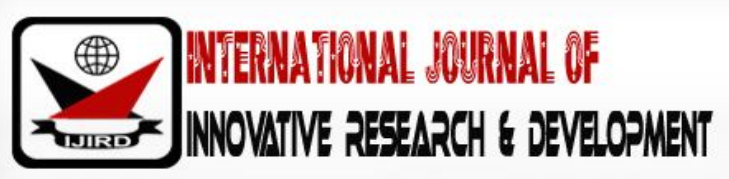

ISSN 2278 - 0211 (Online)

\section{Psychosocial Dynamics Underlying the Reintegration of Spinal Cord Injury (SCI) Survivors into the Kenyan Education System}

\section{Winfred Mugure}

Ph.D. Student, University of Nairobi, Kenya

\begin{abstract}
:
The very nature of SCI poses many psychosocial challenges to its survivors. Yet, the impact of the effects is determined by the availability of psychosocial support or the lack of it thereof. Survivors to whom this support is availed have a higher likelihood to rehabilitation and reintegration. An ex facto study design was utilized with the 352 respondents to whom the study instruments were administered being aged between 16 and 35 year. The study tools comprised of a structured questionnaire and scheduled structured interview. The research established the significant contribution made through psychosocial interventions in the reintegration of SCI survivors to functionality and learning. The article makes a significant and authentic contribution to the body of knowledge on psychosocial care and its impact on the reintegration of spinal injury survivors into the Kenyan education system. In conclusion, the study indicates that psychosocial interventions play a crucial role in the reintegration of SCI survivors; which in turn enhances their personal development.
\end{abstract}

Keywords: Dynamics, education system, psychosocial, reintegration, spinal cord injury (SCI) survivors

\section{Introduction}

Spinal cord injury is one of the most devastating injuries,which causes disability and inability to feel the limbs and control the functions of the internal organs; even though normal cognitive functions usually remain (Ann,2007). SCI is a neurological injury resulting in varying degrees of paralysis, sensory loss and sphincter disturbance, which may be permanent and irreversible (Holtz, 2010). Although SCI is a relatively uncommon, its effects can be devastating (Thomas, 2010). The injury results in permanent paralysis of voluntary muscles and loss of sensation below the lesion, which is associated with reduced mobility in functional independence, impairment of social and vocational activities, and negative influence on the person's well-being (Taslemski, 2008).

Effective reintegration of spinal cord injury (SCI) survivors into the learning system has been identified as an invaluable tool in self-development. Such reintegration elevates personality dynamics including self-perception, independence and initiative as well as a broadening of ones scope with regard to making informed choices and decisions (Holtz, 2010). According to Edelle (2009), this underscores the need for accessibility to education, facilitates an emotional balance that is receptive to learning, and a conforming infrastructure for optimum acquisition.Lack of educational empowerment becomes the survivors' greatest disability, makes them vulnerable and exposes them to deprivation and exclusion, inhibiting their holistic recovery- physical, mental and emotional (Fabes, 2012).

Studies of SCI survivors' potential, challenges and dispositions with regard to self-development have been done in the United Kingdom, Australia, India and Mexico. According to the World Health Organization (WHO) report (2013), these studies indicate that psycho-social empowerment and availability of learning opportunities (formal and informal) can profoundly influence the survivors' lives and development in a multitude of ways.The effects of SCI are diverse and wide-ranging as projected by a World Health Report (2010); and the subsequent gross physical impairment giving rise to poor self- concept and emotional dysfunctions. The report however made recommendations for psychosocial interventions such as trauma psycho-education, problem solving, self-assessment, group therapy and vocational rehabilitation. The report further indicates that such services are only available in developed countries like the U.S and U.K where they are readily accessible, highly subsidized; and even offered free in some cities. Most survivors who access such services have been reported to have comparatively elevated emotional health, enhanced coping skills and higher prospects for the future as compared to those survivors who do not access such services. 


\subsection{Importance of Guidance and Counselling}

The inconceivable emotional and psychological stress which SCI survivors face requires supportive counseling and guidance (Dewey, 2004). According to Franceschini (2008), such dynamics, when offered in a compassionate manner, enable the survivors to go through the transition of neurotrauma journey in an easier way. Franeschini further submits that SCI survivors get functionally disabled by emotional inability, irritability, depression, range and apathy, among other conditions which requires life-skills counseling.Freeman (2010) conducted a study in India aimed at assessing psycho-social problems, evaluating their impact and remedial measures which involved fifty survivors. After remedial measures and follow-up which was done after six months, the study concluded that simple instructions and interventions are effective in decreasing the psychological effects of SCI, and recommended that health care providers incorporate the same in the rehabilitation regime of SCI survivors.

Epidemiological surveys and multi-centre research on intervention have been done in the developed world, and psychosocial imbalance identified as a primary effect of SCI. In the West for instance, the rate of return to training for vocational readiness is $41-87 \%$ (Gosneys, 2011).Gosney attributes this to the availability on psycho-social support.

Such support addresses common neuropsychological deficits, such as poor concentration ability, impaired memory function, altered problem-solving ability, anxiety and depressive disorders associated with SCI (North,2006). A study by Friedman (2004) among Sichuan earthquake SCI survivors identified psychosocial disorders as a dominant aspect of which, $20-25 \%$ manifested anxiety disorder, 30-40\% depressive disorder, while 10-40\% manifested symptoms of post traumatic stress disorder.

Counseling as indicated in such studies is perceived to be the act of helping a person to rediscover himself and his potential, to see who he really is, what he has or does not have, what he can do easily, what he can do with difficulty and what he probably cannot do at all (Arbuckle, 2006). It is an accepting, trusting and safe relationship in which the clents learn to discuss openly what worries and upsets them, to define precise behaviour goals, to acquire the essential social skills and to develop the courage and self-confidence to implement desired new behavoirs (Ohlsen, 2005). Counselling involves a process of problem solving with people who are basically emotionally healthy but who are being confronted by a temporary life problem or issue related to a crisis or a developmental stage (Nelson-Jones,2004). On this premise, the overall aim of counselling is to provide an opportunity to work towards living more satisfactorily and resourcefully (Chauhan,2000). According to Egan (2004), counselling facilitates change in individuals to enable them make future decisions. It helps an individual to find the opportunities that are right for him and use his experience to cope with current realities. He further submits that as a service, counselling is designed to help individuals to voluntarily change their behavior by clarifying their ideas, perceptions, attitudes and goals.

Guidance is defined as a process that is developmental in nature by which an individual is assisted to understand, accept and utilize his abilities, aptitudes and interests (Newton, 2003). According to Egan (2004), guidance is a process of helping individuals through their own effort to discover and develop their potentialities for personal happiness and social usefulness. Sharma (2007), submits that guidance is the assistance given to an individual in order to make intelligent choices and adjustments; it involves personal help given to someone. It is designed to assist a person decide where he wants to go or how he can best accomplish his purpose.It assists him to solve problems that arise in his life. SCI does not only immobilize individuals, but also subjects them to reduced level of mental and physical health, most survivors though may not suffer acute psychological disturbances. Sharma, (2006) equates the emotional effects of SCI to the grief of bereavement. Due to the impact of such an injury on an individual's development, a survivor requires psychosocial support services to help him to utilize his own coping resources (Sign, 2005).

The ability to cope after SCI enhances life satisfaction which Neugarten, Havghurst and Sipski (2006) described as a psychological state that may broadly be associated with psychological well-being. According to Decker and Crowell (2009), life satisfaction is compromised or lowered by SCI. Anderson (2009) demonstrated that people with SCI scored a lower mean of 10.76 in life satisfaction in a maximum rate of 20 as compared to the average score of 16.2 of the general population in a study involving SCI survivors in the California Trauma Centre.

In a similar study at Magee Rehabilitation Hospital, O'Leary (2006) established that $90 \%$ of the participants without disabilities were either very satisfied at $70 \%$ or somewhat satisfied at $50 \%$ with life, whereas $68 \%$ of the participants with SCI, were either very satisfied at $57 \%$ or somewhat satisfied at $41 \%$. In order to help the SCI survivors to elevate their life satisfaction, psychosocial intervention projected towards social adjustment was offered. Such included psychological counseling and minimizing of social barriers. The survivors were offered vocational guidance and training opportunities for self-empowerment leading to independence (Krause, 2006). Krause further submits that after the intervention, 48\% of the SCI survivors gained full autonomy and could work and support themselves, while $26 \%$ could engage in routine activities independently. Generally, $60 \%$ of the survivors changed their jobs to those that suited their changed dispositions.

Counseling would enable such survivors to live beyond learned helplessness, enable them to utilize fear coping resources and promote their well-being (Kelly, 2011). Gordon further stipulates that a Counselor would be expected to identify the emotional needs of such a survivor and put interesting and reconstructive measures in place. This would provide an enabling atmosphere for coping, strategizing, making decisions and planning for the future.The counseling provision should be a prerogative of every spinal cord injury survivor rather than being handled as a service mainly reserved for survivors with psychological disorders.The study further stipulates that if their goals in life, such as those achieved through education 
empowerment are not met, their challenges may become insurmountable. As such, they may often become confined by feelings of depression, frustration, anxiety and helplessness, while others may even end up devastatedand incapable.

\subsection{Statement of the Problem}

Sharma, (2006) studied the challenges of marginalized populations in accessing education in Australia, and found out that education has been progressively viewed as a crucial means of resolving individual and social hitches, especially amongst those who are marginalized minorities; ignored and un-served. An SCI survivor's ability to access education empowers them the needed skills for growth and development. These in turn increases their chances for self-management and self-efficacy. In this way, they don't miss out on making a contribution in societal development. The use of psychosocial measures such as guidance and counselling can greatly enhance the chances of reintegrating SCI survivors and give them a chance to reenter learning; in order to give them a chance to live a meaningful life.

\subsection{Importance of Study}

The larger study in part aimed to find out the various post trauma factors affectingSCI survivors. It also determined psychosocial measures specific to SCI survivors. These interventions were meant to help in their reintegration. Besides, understanding SCI survivor post trauma issues would greatly inform best practice guidelines and policies for SCI survivor reintegration.

\subsection{Objective}

This article is drawn from one objective from a larger Kenyan study carried out in 2017. The specific objective on which this article is based aimed to determine the psycho - social underlying forces influencing the reintegration of SCI survivors into the Kenyan education system.

\section{Methods}

This expost facto research design used in the study which investigated the variables without any manipulation (Tuckman, 1978). The research investigated 364SCI youths who got injured before they were 21 years of age; and satisfy the inclusion criteria of the Kenyan paraplegic organization. Data gathering employed a structured questionnaire and interview guides for the psychosocial caregivers and SCI survivors as well.

\subsection{Participants}

The data on table 1 reveals that the percentage of respondents below 13 years of age is comparatively low, which corresponds with the traumatic etiology presented on figure 4.1. The mean age of the SCI survivors was 24.8 years $-\mathrm{s} . \mathrm{d}=3.0$ (range 06-34 years) at the time of accident. The respondents presented at a mean of 2.4 years after injury (range 6 months to 20 years; $\mathrm{SD} \pm 4.34$ ) after injury.

\begin{tabular}{|c|c|c|c|}
\hline & \multicolumn{2}{|c|}{ Sex } & Percentage \\
\hline Age & Male & Female & $3.12 \%$ \\
\hline $6-13$ & 06 & 05 & $13.06 \%$ \\
\hline $14-18$ & 24 & 22 & $83.8 \%$ \\
\hline $19-35$ & 184 & 111 & $100 \%$ \\
\hline Total & $214(60.8 \%)$ & $138(39.2 \%)$ & \\
\hline \multicolumn{3}{|c|}{ Table 1: Age of Respondents by Gender } \\
N=352
\end{tabular}

\section{Findings and Analysis}

Figure 1 presents data on the accessibility of rehabilitative therapy; $26 \%$ are able to access this therapy in hospital; while $16 \%$ receive rehabilitation at home. This was attributed to the level of functionality as survivors with injuries high up at cervical 4 to $5\left(\mathrm{C}_{3}-\mathrm{C}_{5}\right)$ find it comparatively difficult to engage in movements and transfers which involve transporting one from one point to another. Majority of the SCI survivors however, 58\%, do not access rehabilitative therapy at all, which may tend to compromise their health and psychosocial balance. 


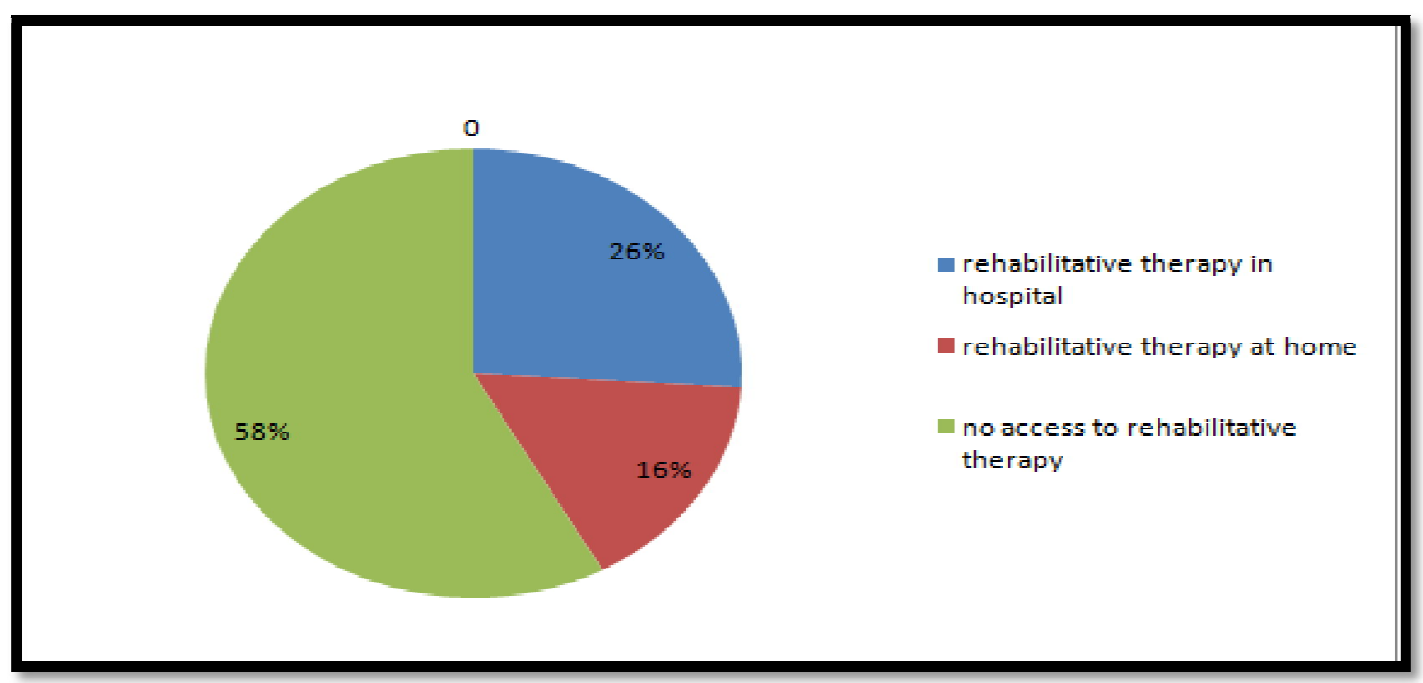

Figure 1: Access to Rehabilitation Therapy $\mathrm{N}=352$

Most of the SCI survivors needed supportive care and lived with others for the same reason. Table 4.9 demonstrates that $58.5 \%$ lived with their immediate family while $10.8 \%$ lived with their extended family. This could be attributed to the central role family plays in one's personal development. A few (5.4\%) live with friends. These $54 \%$ included independent young adults pursuing personal development avenues in cities away from their homes. Above a third (31\%) live with hired minders, most of these are tetraplegics whose functional ability is relatively poor. More than half (54\% SCI) survivors live alone; such includes those who have gained total autonomy and are either formally or self-employed. Only $1.1 \%$ live in charitable institutions and these were basically abandoned in childhood after sustaining SCI.

\begin{tabular}{|c|c|c|}
\hline & Frequency & Percentage \\
\hline Immediate family & 206 & $58.5 \%$ \\
\hline Extended family & 38 & $10.8 \%$ \\
\hline Friends & 19 & $5.4 \%$ \\
\hline Hired minder & 31 & $8.8 \%$ \\
\hline Alone & 54 & $15.3 \%$ \\
\hline Charitable institutions & 04 & $1.1 \%$ \\
\hline Total & 352 & $100 \%$ \\
\hline
\end{tabular}

Table 2: Social Support Dimensions

$\mathrm{N}=352$

The respondents associated several benefits to reintegration into the education process as indicated on table 2. A large number (98\%) noted that reintegration had enhanced their socio-economic potential while $93.9 \%$ indicated that it had improved their quality of life. Another great number (89.8\%) attributed their personal growth to reintegration while $79.6 \%$ felt it had led them to a great measure of life satisfaction. Reintegration into learning had given $69.4 \%$ a sense of purpose, elevated mental stimulation and enhanced higher activity level to $29 \%$ and $28 \%$ respectively. All the SCI survivors who responded to this segment expressed a general feeling of self-efficiency and were among the $24 \%$ who felt they had attained their aspirations to varied degrees.

\begin{tabular}{|c|c|c|}
\hline Benefit & Frequency & Percentage\% \\
\hline Life satisfaction & 39 & $79.6 \%$ \\
\hline Higher activity level & 28 & $57.1 \%$ \\
\hline Better quality life & 46 & $93.9 \%$ \\
\hline Socio-economic potential & 48 & $98.0 \%$ \\
\hline Mental stimulation & 29 & $59.2 \%$ \\
\hline Increased social contacts & 39 & $79.6 \%$ \\
\hline A sense of purpose & 34 & $69.4 \%$ \\
\hline Personal growth & 44 & $89.8 \%$ \\
\hline
\end{tabular}

Table 3: Benefits of Reintegration into the Education Process 
Figure 2 presents the support systems that anchor the SCI survivors emotionally in the absence of a psychological caregiver. The data indicates that majority of the survivors depend on their church ministers at $34 \%$ while $28 \%$ entrusted the provision of this support to a friend. Another group (19\%) of the survivors sourced for support from their physiotherapists, $12 \%$ from their doctors while of the $7 \%$ sought support from other care providers from other disciplines.

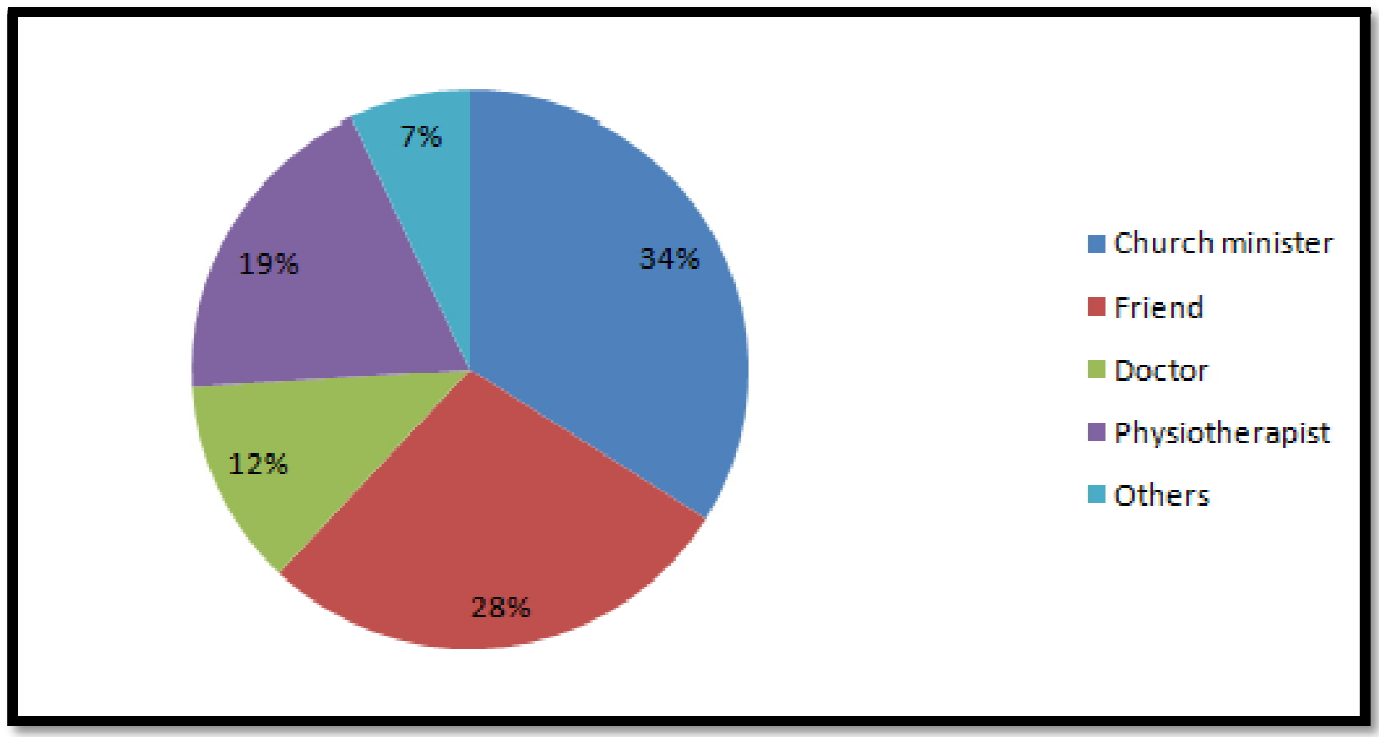

Figure 2 Emotional Support Providers of Choice $\mathrm{N}=352$

The results are in contrast to a study by the preventive medicine council (2006). In this 2006 study, 86\% of the survivors had direct access to a counselor whom they could call at any time for consultation. They even had an added advantage cum option in the office of social work within the proximity of their residence. The easy access to this kind of support is an elaborate demonstration of the advanced information technology and strong social networks in the U.S On the other hand, the data from this study underscores the need to strengthen the SCI care network in which survivors are able to access support whenever in dire need.

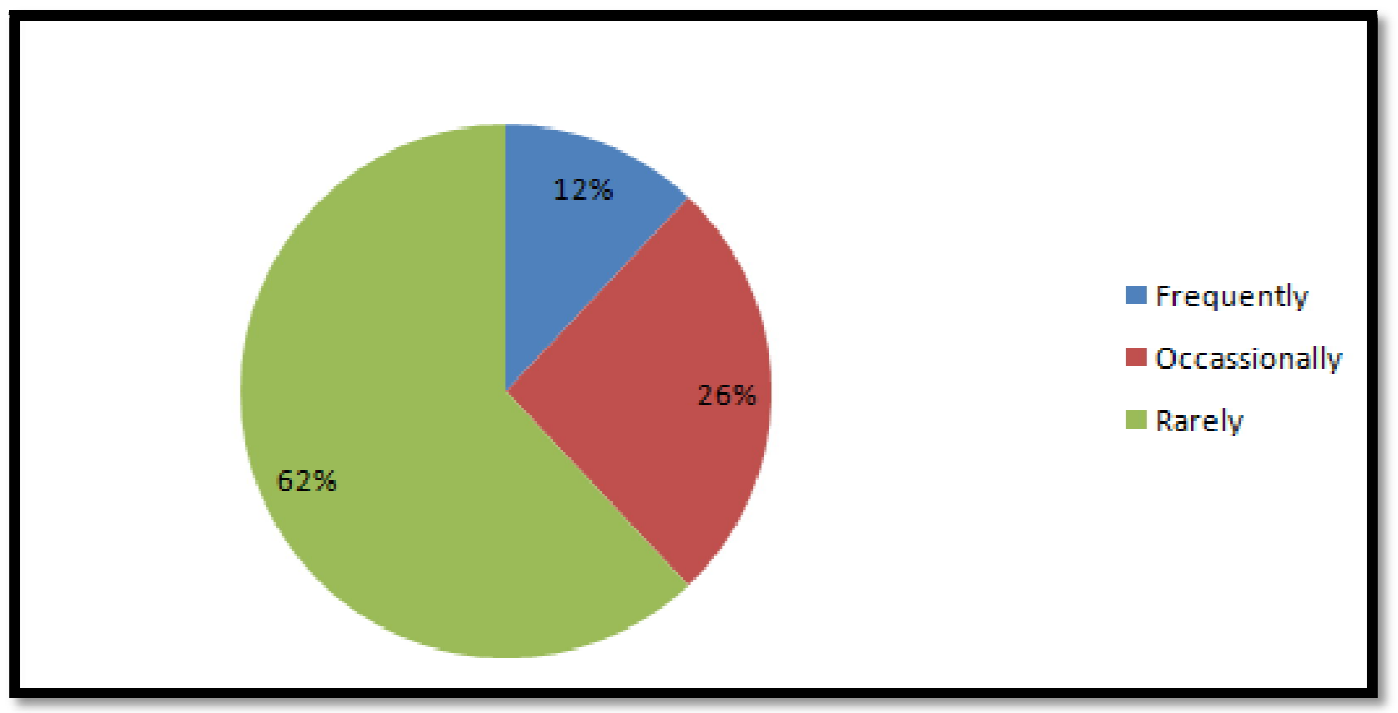

Figure 3: Frequency of Counseling Sessions

$$
\mathrm{N}=352
$$

The SCI caregivers presented their sequence of engagement with their counselors as indicated on figure 3. Only $12 \%$ consulted their counselors frequently. This could be as a result of extremely low counselor client ratio at the rehabilitation centers which stood at 1:138 and 1:126 for Mbagathi and Mama Lucy county hospitals respectively. Only a few (26\%) consulted occasionally, while $62 \%$ consulted rarely. This frequency accounts for the marginal post injury psychosocial outcomes. 
The psychosocial caregivers explore a range of SCI issues with the SCI survivors. Table 4.20 presents the rates and sequence of coverage from the survivors' perspective. Social problems rated the highest at $81 \%$ implying that it is the most popular issue of concern while issues such as intellectual ability, priorities in life and rights of the SCI as a person with disability as well as those related to special needs education are never discussed. While the survivors benefit from the exploration of a range of SCI related issues, the findings indicate a comparatively high rate of avoidance for sensitive but crucial issues that may empower the survivor.

The SCI survivors encounter coping and adjustment problems to an extent that require intervention. Figure 4.17 presents data from the psychosocial caregiver's responses to the trends of coping indicating that $69 \%$ coped well after the psychosocial encounter while 31\% needed specialized intervention. Although the needs requiring intervention are varied, a general feeling that an assessment and subsequent action in relation to the coping and adjustment trends of the survivors is crucially important was expressed. The study established that for most respondents, SCI was associated with negative emotional reactions. A psychological diagnosis warranting intervention occurred in $31 \%$ of the respondents hence, a majority of the survivors were able to cope and adjust well.

There were considerable variations in the counseling outcomes within the population of SCI survivors across age and socio economic groups. The SCI survivors expressed different views regarding the value gained from counseling sessions in relation to their self-development in table 4.27 . A good number $(39.2 \%)$ rated the encounters as very helpful, $25 \%$ as helpful and $18.9 \%$ as fairly helpful. Counseling was not helpful to $7.4 \%$. This could be attributed to survivors' expectations which psychosocial caregivers may not have identified as well as inadequate training and experience on the part of the counselors. A few $(9.5 \%)$ of the survivors did not state their reasons.

\section{Conclusions}

The study in part established the effects of post injury psychosocial measures on the SCI survivor's functionality and reintegration

This study, which focuses on the dynamics involved in psychological adjustment processes following SCI and the impact on the reintegration into the learning system established that experiencing a SCI poses a great challenge and requires adaptation and resilience to cope in order to develop strengths and discover new ways of adjusting not only physically, emotionally and socially but also in vocational dynamics. The study established that psychosocial intervention involves empowering the SCI survivor to adjust to a very different lifestyle with the re-establishment of roles, relationships and opportunities that express one's own identity. Psychological adjustment is as such influenced by the strategies employed during the post injury rehabilitation phase and this marks the beginning of the healing process.

This study established that social relationships and support also play an important role in enhancing emotional and socio-economic recovery and resumption of studies after SCI. A large number (72\%) of the psychosocial care providers indicated that perceived social support serve as a protective factor against extreme anxiety, depression, and decreased activity levels. However, challenges exist in the recognition and management of the psychological and social dimensions of SCI. A few others (31\%) of the SCI survivors were reported to be on special programs, considered to be moderate intervention. Of those on special intervention, $22 \%$ were on marital counseling especially to manage sexuality malfunctioning while the rest were on counseling programs for adjustment. These interventions were all considered as moderate, implying that none of the SCIsurvivors was on an intensive intervention program. All those on addiction programs were reported to be responding to therapy in a fairly positive manner, apart from one of them, $(0.28 \%)$ who was in preparation for a residential rehabilitation program. As such, all the others were reported to be responding positively. For those who required intervention as indicated above, negative symptoms were being treated to enable them achieve adaptive emotional recovery, crucial for goal setting and resumption of studies.

The study also revealed that psychosocial intervention played a significant role in the SCI survivors' well-being. A high percentage (83.1\%) of the respondents who have had contact with a counselor generally appreciated the therapists for being knowledgeable, concrete, structural and empathetic; essentially all of the psychosocial care recipients articulated the positive impact of psychosocial therapy and counseling they had received. The study however revealed significant differences in the level of intervention as well as distinctive approaches in the mode of providing care, which have the potential to impact the outcomes of the intervention. These are accounted for by the available social capital that the SCI survivors are supported with. The results were consistent with Singal (2009) who indicated that young people with disability are greatly disadvantaged in terms of the social capital which should ideally be their anchor especially in the turbulence of their transitions. For instance, the highest percentage of psychosocial caregivers attending to them were social workers, some only trained to peer certificate level with marginal exposure to counseling psychology yet, entrusted a significant role that requires a considerably high multidisciplinary exposure to psychology to enable them address issues such as trauma, health, human development and the cognitive dimension in counseling.

Among individuals with SCI in the education system at the time of the injury, psychosocial intervention facilitated post injury reintegration into learning of $88 \%$ of those who accessed the services which translates to $37 \%$ of the sample population. Return to school (RTS) was higher in survivors who had less severe injuries and higher functional ability - the rate of the paraplegics as compared to tetraplegics was $69 \%$ and $31 \%$ respectively. Individuals who sustained SCI in childhood or adolescence had higher education integration rates. 
The psychological intervention in the occasion of SCI was shown to strengthen individual survivor's functional, structural, emotional and developmental needs, empowering them to restore their pre-injury dignity and aspirations. In addition, the study revealed that more autonomy and independence characterize those SCI survivors who get reintegrated into the education system and pursue their goals.

The results of this study, suggests that post-injury counseling is functional to successful achievement trends and positive behaviour articulations instrumental to psychosocial adjustment and personal development. The findings are not only projected towards the way in which personal development fits into the total psychological structure of the SCI-survivor, but also how the SCI survivor develops strong and well internalized desires for the same development within the context of emotional and socio-economic strain as a result of SCI.

\section{5. .Recommendations}

The study underscores the importance of psychosocial interventions in the rehabilitation, adjustment and reintegration of SCI survivors. Recommendations are therefore made for rehabilitation institutions especially the spinal cord injury hospitals which receive SCI survivors to ensure that psychosocial interventions are integrated into the rehabilitation therapy program in order to manage the related emotional and psychological issues associated with SCI to improve on the measures of coping and self-development. Government should also ensure that these interventions are made affordable or even free of charge for the survivors.

\section{References}

i. Edelle, C. (2009). Spinal Cord Injury. Philadelphia: F. A. Davis.

ii. Fabes, R.O. (2012). Practical Counselling. Chicago: Thomas more press.

iii. WHO

iv. Dewey, J. (2004). Human Nature and Conduct: An Introduction to Social Psychology. New York: Henry Holt.

v. Fransceschini, M. (2003). Longitudinal Outcome 6years After Spinal Cord Injury. Spinal

vi. Cord, $41,280-5$.

vii. Freeman, M. (2010). Parents Functioning in Families Of Pre-Adolescents With Spina Bifida:

viii. Longitudinal Implications tor Child Adjustment. J. Fam Psychol. 2004,18:609-619.

ix. North, R. S. (2006). Individual and Group Therapy. London: Addison Wesley.

x. Gosney, S. M. (2011). Post- Traumatic Response. NewYork: Demos Books.

xi. North, R. S. (2006). Individual and Group Therapy. London: Addison Wesley.

xii. Friedman

xiii. Arbuckle (2006)

xiv. Ohlsen (2005)

xv. Nelson, J. R. (2001). Practical Counseling and Helping. (2ndEdition). London : Cassell.

xvi. Chauhan 2008 Egan 2004

xvii. Sharma, S. C. (2006). Assessment of sexual functions after spinal cord injury in Indian

xviii. patients.International Journal of Rehabilitation 29, 17-25

xix. Singh, R. (2005). Sexuality and women with spinal cord injury. Sexuality and Disability, 2005, 23 (1) 21-33

xx. Neugaten.....(2006)

xxi. Decker (2008)

xxii. Krause, W. J. (2008). Emotional Adjustment and Spinal Cord Injury. London: Sage.

xxiii. O'leary 2006

xxiv. Kelly E. H. Relationships between the psychological characteristics of youth with spinal

xxv. Cord injury and their primary caregivers.Spinal Cord. 2011.49: 200-205.

xxvi. Tuckman 1998

xxvii. Preventive medicine 